\title{
ADAPTATION OF CLIMATE SMART AGRICULTURE CONCEPT IN KAZAKHSTAN, PROS AND CONS
}

\author{
Anna Viter \\ MSc in Rural Development and Agribusiness \\ Faculty of Economics and Social Sciences, Szent István University \\ E-mail: anna.viter24@gmail.com
}

\begin{abstract}
The main purpose of this research is to see new examples of climate smart farming methods, how they might increase agricultural productivity and to be resilient to climate change. The object of the research is Climate Smart Agriculture holistic concept. The subject of the research is the relationships between farmers and governments of different countries. Food and Agriculture Organization is one of the major objectives to achieve food security and the agricultural sector is a key driver of food security. Having sustainable agricultural growth is necessary for achieving global food security. In order to become resilient to disasters, increase productivity and incomes and contribute to mitigation there is a relatively new holistic concept called Climate Smart Agriculture. Climate Smart Agriculture project is trying to build a model for the kinds of practices, policies and investment proposals and making resources of financing that we need to achieve food security.
\end{abstract}

Keywords: Climate Smart Agriculture concept, Food and Agricultural Organization, World Bank, food security, climate change, CSA methods, no-tillage method.

Achieving the four dimensions of food security such as availability and access to food; utilization of food for adequate nutrition and food supply stability) needs to be the overall goal of food production and distribution systems in developing countries including Kazakhstan. Multiple components contribute to food security, and adapting food systems to climate change involves a diversity of approaches and resources.

\section{Introduction}

Thus, taking into consideration that this concept (CSA) is relatively new and not so well developed such countries as Malawi, Zambia, Vietnam and the Republic of Kazakhstan decided to take an experiment and applied different climate smart agriculture methods. Within the framework of this concept, these four countries revealed advantages and disadvantages of CSA.

Climate change studies in Kazakhstan as well as in the whole Central Asia are very important because their natural resources and economy are significantly vulnerable to climatic changes due to limited water resources, a large territory and peculiarities deriving from its geographical location at the centre the huge Eurasian continent.

The sectors and regions in Kazakhstan most vulnerable to climate change were identified as water resources, agriculture (wheat production), grasslands, mountain ecosystems, and the Caspian Sea coastal zone.

The main scientific results from these studies are that: 
- the mountain areas of the south and southeast of Kazakhstan are vulnerable to climate change impact;

- the expected rise in level of the Caspian Sea, in combination with storm surges, will cause high sea water levels;

- the Caspian Sea level rise will cause an elevation in groundwater level in the coastal zone;

- the estimated economic and social damage caused by climate change in these areas is significant.

Food and Agriculture Organization is one of the major objectives to achieve food security and the agricultural sector is a key driver of food security. Having sustainable agricultural growth is necessary for achieving global food security.

In order to become resilient to disasters, increase productivity and incomes and contribute to mitigation there is a relatively new holistic concept called Climate Smart Agriculture.

Climate Smart Agriculture project is trying to build a model for the kinds of practices, policies and investment proposals and making resources of financing that we need to achieve food security.

Achieving the four dimensions of food security such as availability and access to food; utilization of food for adequate nutrition and food supply stability) needs to be the overall goal of food production and distribution systems in developing countries including Kazakhstan. Multiple components contribute to food security, and adapting food systems to climate change involves a diversity of approaches and resources.

1. Building an evidence base to look out what are the practices and changes in agricultural systems that will give adaptation to climate change given the specific kinds of projective changes but also can give mitigation benefits.

2. Barriers that farmers will face during adopting these practices.

3. Looking at risk management. Risk is undoubtedly affects what farmers do. Huge part is to understand how risk changes the barriers farmers face in adopting new practices and how to overcome them.

4. Building coherent policy and strategic framework that combines the agricultural development, food security and climate change.

5. One of the major outputs of the project is to put all together in an investment proposal. So that, countries have the capacity to move ahead with large CSA investments and then it would be funded not only from agricultural sources of finance but also from climate change sources of finance. These new urgent sources to support the adaptation and mitigation.

Climate Smart Agriculture project involves 5 different pieces 
So, achieving all this pieces in a proper way will take a considerable amount of time and professional skills not to mention to collect all the data for the investment proposals and implement them on practice.

Taking into consideration the fact that CSA is relatively new holistic concept and it wasn't applied in many countries that much, though there are some experimental projects in several countries in order to reveal advantages and disadvantages of CSA methods.

For example, in Malawi and Zambia the project which involves reduced tillage, permanent soil cover and crop rotation was promoted.

Conservation agriculture is able, at least potentially, increase productivity through better soils and help farmers adapt to climate change through better water retention. It also might help mitigate climate change by trapping carbon in the soil.

However, project analysis indicates that farmers in the two countries have difficulties adopting the full climate smart farming package, because, for instance, they need crop residue for animal feed instead of soil cover. Sometimes the problem is that farmers are too poor to wait several seasons for the benefits of the practice to materialize.

However, the project is also finding that climate change is already altering which agricultural practices work best for farmers, which could increase the appeal of climate agriculture.

In Zambia, analysis of climate data shows an increasingly late start of rains in some areas. Since crops are only planted after the first rains, late rains mean late planting, which can seriously shorten the growing season. Project research shows that farmers in these areas of variable rainfall and late start of rains are the most likely to maintain climate agricultural practices, which has the advantage of preparing the land before rains arrive.

In Vietnam, at the project site in the northern part of the country, maize is planted on sloping land all the way to the tops of mountains, which theoretically should be covered only in forest. Once the maize is harvested, the rains come, clearing away the soil. The erosion has led to landslides, with loss of life.

Project researchers studying Vietnamese climate data have found that climate variability is increasing, which will sharpen the erosion issue.

In response, the project is looking at more sustainable land management practices but also the use of long standing crops such as coffee and tea, which unlike maize can stay in the ground for 30-40 years. However, coffee and tea production require years to generate high returns, which is a challenge for farmers currently growing maize, which has strong demand and fetches a high price.

One of the brightest examples of CSA in Kazakhstan is the method called no-tillage agricultural project, launched in 2012. According to the recent data (Picture 1) it is clearly seen that the Republic of Kazakhstan takes almost the same place as China does and occupies $1 \%$ of no-till adoption among all represented countries. 


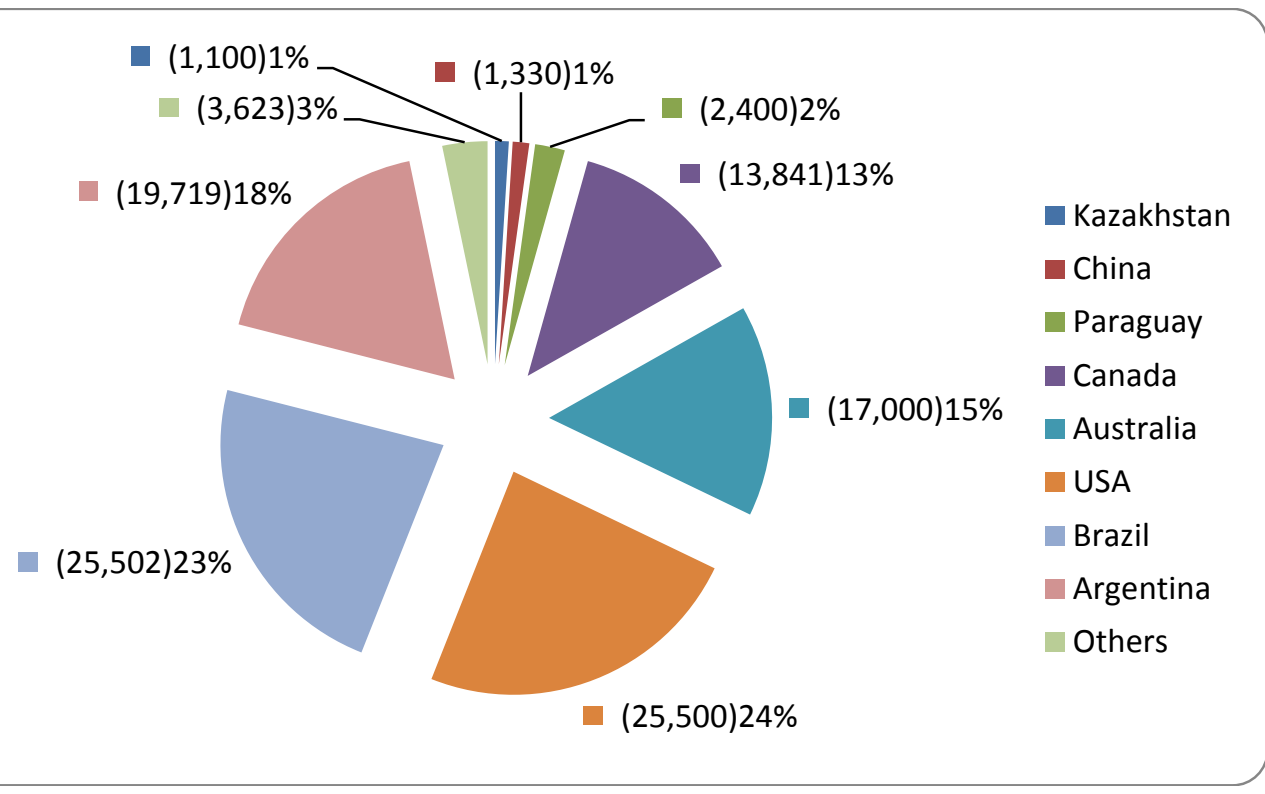

Picture1. Extend of no-tillage adoption worldwide (*1000 ha) 2011-2012

Obviously, the adoption of no-till in developing countries is urgently negligible by comparison with the expansion of this technology in developed and emerging countries of North and South America.

Thus, the FAO and the World Bank estimated that just in 2012 the adoption of this technology resulted in 2 million tons of additional wheat grain, which is enough to feed some 5 million people for a year. So far, the new method is showing $30-40 \%$ yield increases, cutting cultivation costs, and reducing soil erosion.

With support from the international organizations such as FAO, the World Bank and the International Maize and Wheat Improvement Center Kazakhstan's farmers are relying more on no-tillage. However, the main cons to rely upon only no-till are:

The potential of no-till agriculture is limited in drought prone areas, particularly in the semiarid areas where annual rainfall is less than $800 \mathrm{~mm}$ and the dry season lasts more than five months.

- Some farmers need to learn more about no-till in order to abandon ploughing, which is, after all, one of the foundations of their craft for millennia. Indeed, experts warn, a major risk is the potential failure of early adopters, which could create the wrong impression of no-till and scare other farmers off.

- Another possible barrier is the cost of investment.

It is estimated that farmers in northern Kazakhstan have invested about US\$200 million to equip their farms with no-till machinery. The return on these investments is high, but the initial costs might scare some farmers away.

- $\quad$ Finally, Kazakh farmers need to be encouraged to plant crops other than wheat, to allow for crop rotation to strengthen the soil.

However, experts are arguing that the real key to success is to continue extending up no-till; conservation agriculture saves fuel, soil, and time. The longer farmers use no-till, the greater the fertility of the soil. In addition, no-till is also capturing carbon, as healthy organic matter, in the soil, contributing to climate mitigation. 
In fact, sequestering 1.5 million tons of carbon dioxide a year is equial of taking 290,000 cars off the road. So, by adopting no-till, Kazakh farmers are working to protect crops from climate change, which is a practical example of climate smart agriculture. Thus, from all experiments mentioned above it is right to say that the four project countries have different physical, economic, social and cultural characteristics, so that the project has found opportunities for the countries to learn from each other.

The project also found that variances in how the weather is changing from country to country as well differences in the capacities of famers, institutions and economies - mean that no there is no single solution which will be suitable for each country, although the approach to identifying appropriate measures is universally applicable.

In sum up briefly, the initial outcome of the project is that it defines challenges and opportunities for climate-smart agriculture for these countries and produce strategic plans tailored to each country's own level. While not all solutions identified will be universally applicable, farmers and governments can learn a lot about how countries could take similar steps and start shifting to this approach to agriculture.

\section{References}

1. Www.fao.org

2. Www.climate.kz

3. www.eco.gov.kz

4. www.ecoclimate.kz

5. www.climate.kz/eng/? $\mathrm{m}=\mathrm{html} \& \mathrm{cid}=26$

6. www.un.kz

7. www.undp.kz/projects/start.html

8. www.oopt.kz/podvedomst_org/rkgp/kaz_lesstroi 